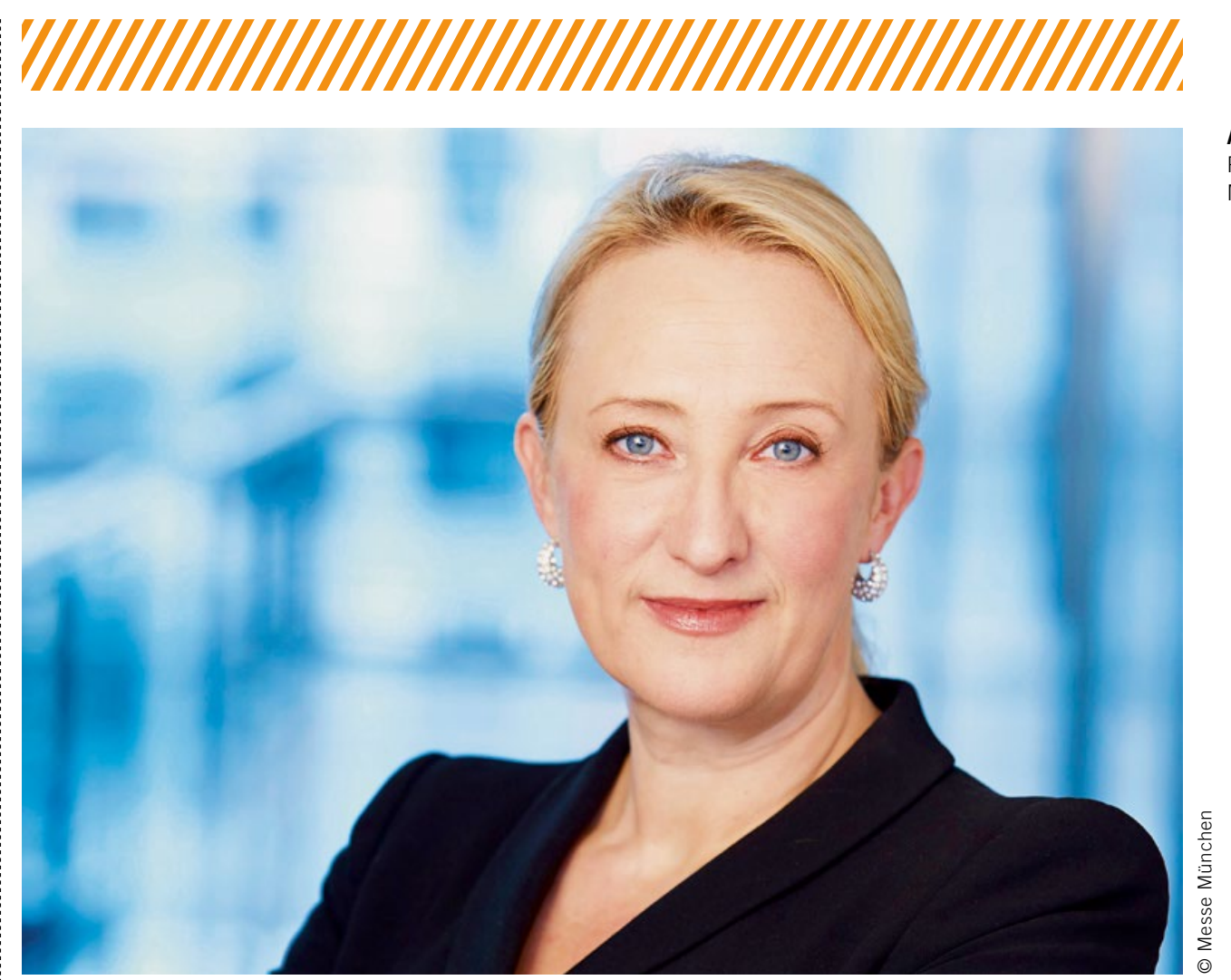

Angela Marten

PR Manager Electronica,

Messe München

\title{
Akzente im Umbruch der Automobilindustrie
}

Die Elektronik ist Innovationstreiber der Automobilindustrie. Ein Großteil der wichtigsten Neuerungen kommt heute nicht mehr aus der Fahrzeugtechnik, sondern aus der Mikroelektronik und Software. Rund 30 \% des Produktionswerts eines Autos entfallen auf Elektronik und Elektrotechnik, schätzt der Zentralverband Elektrotechnik- und Elektronikindustrie (ZVEI). Das ganze Universum der Automobilelektronik präsentiert sich vom 8 . bis 11 . November auf der Electronica in München. Aussteller aus über 50 Ländern zeigen auf der Weltleitmesse der Elektronik, wie das Fahren von morgen bequemer, sicherer und nachhaltiger wird.

Die Automobilbranche befindet sich im Wandel. Intelligente Energieversorgung, Vernetzung nach innen und außen, höchstmögliche Fahrsicherheit und neue Komfortfunktionen bestimmen die Neuausrichtung. Vernetzte Systeme, verbesserte Sensoren für Fahrerassistenzsysteme und neue Lichttechnologien mit LED, OLED und Laserlicht erfordern zudem ein stärkeres Zusammenspiel der Steuergeräte und Aktuatoren. Leistungsfähigere Bauelemente und aufwendigere Software sorgen für Komfort und Sicherheit beim Fahren.

In der deutschen Mikroelektronikindustrie ist der Bereich Automotive mit $44 \%$ Produktionsanteil das wichtigste Segment. Die zunehmende Bedeutung dieses Zukunftsmarkts zeigt sich auch in den Messehallen der Electronica: Von den mehr als 2800 Ausstellern präsentieren über 800 Unternehmen Lösungen aus der Automobilelektronik.

Auf der Electronica Automotive Conference am 7. November tauschen sich Experten aus dem In- und Ausland über Technologietrends aus, die tragende Rollen im Wandel der Branche spielen. Schwerpunktthemen sind Sicherheit, automatisiertes Fahren und Innenraumelektronik. Unter anderem stehen Vorträge über die Sicherheitsrelevanz von Automotive-SoftwareUpdates und $360^{\circ}$-Surround-Sensing-Technologien auf dem Programm. Weitere Highlights sind die Keynotes „Autonomous Trucks - A Global Perspective”, „Trends in Interior Electronics: Automotive meets CE” und „Semiconductors as a key enabler for the transition of the automotive industry" sowie die PanelDiskussion „The secure connected (selfdriving) car”. Unter den Referenten sind hochrangige Repräsentanten von BMW, Bosch, Daimler, IBM und Infineon.

Vertieft und in einem technischeren Kontext vermittelt werden die Themen der Konferenz im Electronica Automotive Forum. Ob teilautonomes oder autonomes Fahren, neue Innen- und Außenlicht-Funktionen oder bessere Connectivity: Das Forum präsentiert aktuelle Lösungen aus verschiedenen Bereichen. Ausgewählte Beispiele veranschaulichen das Zusammenspiel der Technologien.

Auf der Electronica sehen Sie kompakt an einem Ort, was die Automobilbranche zukünftig bewegen wird. 